\title{
Laparoscopic Right Hemicolectomy for Colon Cancer: Technically Feasible and Safe to Perform in Terms of Oncologic Outcomes
}

\author{
Moo Jun Baek \\ Department of Surgery, Soonchunhyang University Cheonan Hospital, Soonchunhyang University College of Medicine, Cheonan, Korea
}

\section{See Article on Page 42-48}

It has already proved that laparoscopic surgery is not any less inferior to conventional open surgery in terms of its safety and efficacy to treat colon cancer $[1,2]$. From this point of view, this study reviewed the outcomes of laparoscopic right hemicolectomy retrospectively as a treatment of colon cancer. The study was considered to be significant as the outcome of a single surgery although it was not the randomized prospective study with large scale of samples. In South Korea, the outcomes of laparoscopic surgery for colon cancer have been reported but they have not been extensive yet. Therefore, the outcomes of a single surgery such as laparoscopic right hemicolectomy performed by the author of this study are judged to be a good evidence to support the outcomes of laparoscopic surgeries. Nevertheless, this study had several flaws to demonstrate the advantages of laparoscopic right hemicolectomy perfectly comparing to conventional open right hemicolectomy. It is mainly because this study is not prospective study and there aren't control groups as well as the sample size was too small. However, data is collecting prospectively with a larger scale of sample and more solid evidence is expected to be produce with this data. In addition to this, if more surgeons are participated in researches expanding the range of subjects, more reliable evidence will be constructed.

Correspondence to: Moo Jun Baek, M.D.

Department of Surgery, Soonchunhyang University Cheonan Hospital, Soonchunhyang University College of Medicine, 31 Suncheonhyang 6-gil, Dongnam-gu, Cheonan 330-930, Korea

Tel: +82-41-570-3633, Fax: +82-41-571-0129

E-mail: ssurge@sch.ac.kr

(C) 2012 The Korean Society of Coloproctology

This is an open-access article distributed under the terms of the Creative Commons Attribution NonCommercial License (http://creativecommons.org/licenses/by-nc/3.0) which permits unrestricted noncommercial use, distribution, and reproduction in any medium, provided the original work is properly cited.

\section{REFERENCES}

1. Fleshman J, Sargent DJ, Green E, Anvari M, Stryker SJ, Beart RW Jr, et al. Laparoscopic colectomy for cancer is not inferior to open surgery based on 5-year data from the COST Study Group trial. Ann Surg 2007;246:655-62.

2. Jayne DG, Guillou PJ, Thorpe H, Quirke P, Copeland J, Smith AM, et al. Randomized trial of laparoscopic-assisted resection of colorectal carcinoma: 3-year results of the UK MRC CLASICC Trial Group. J Clin Oncol 2007;25:3061-8. 